\title{
Organization and Staffing
}

\section{Nurse Working Conditions, Organizational Climate, and Intent to Leave in ICUs: An Instrumental Variable Approach}

\author{
Patricia W. Stone, Cathy Mooney-Kane, Elaine L. Larson, \\ Diane K. Pastor, Jack Zwanziger, and Andrew W. Dick
}

Objective. To investigate causes of nurse intention to leave (ITL) while simultaneously considering organizational climate (OC) in intensive care units (ICUs) and identify policy implications.

Data Sources/Study Setting. Data were obtained from multiple sources including nurse surveys, hospital administrative data, public use, and Medicare files. Survey responses were analyzed from 837 nurses employed in 39 adult ICUs from 23 hospitals located in 20 separate metropolitan statistical areas.

Study Design. We used an instrumental variable technique to assess simultaneously the relationship between OC and ITL. We estimated ordinary least squares and reduced form regressions to determine the extent of simultaneity bias as well as the sensitivity of our results to the instrumental variable model specification.

Principal Findings. Fifteen percent of the nurses indicated their ITL in the coming year. Based on the structural model, we found that nurses' ITL contributed little if anything directly to $\mathrm{OC}$, but that $\mathrm{OC}$ and the tightness of the labor market had significant roles in determining ITL ( $p$ values <.05). Furthermore, OC was affected by the average regionally adjusted ICU wages, hospital profitability, teaching, and Magnet status ( $p$ values <.05).

Conclusions. OC is an important determinant of ITL among ICU nurses. Because higher wages do not reduce ITL, increased pay alone without attention to OC is likely insufficient to reduce nurse turnover. Implementing interventions aimed at creating a positive OC, as found in Magnet hospitals, may be a more effective strategy.

Key Words. Nurses, workforce, organizational climate, turnover

High turnover has been recognized as a problem in many service industries including health care (Mor Barak et al. 2001). Although it is important to note that turnover, in and of itself, is not necessarily bad, there are inevitably costs 
experienced by organizations that lose workers. In U.S. hospitals, nursing turnover has been reported to range from 15 to 36 percent per year (Hayes et al. 2006). These turnover rates are much higher than those for other health care professionals, which are estimated to be on average 2.3 percent per year (data retrieved May 13, 2005, http://www.bls.gov/jlt/home.htm\#data).

Turnover has been conceptualized as the result of an employee decision making process related to organizational features and perceived alternatives; and intention to leave (ITL) has been found to be an antecedent to turnover (Griffeth et al. 2005). The employees' perceptions of the organizational features such as how decisions are made, leadership, and norms in the work place have been termed organizational climate (OC) (Stone et al. 2005). Staffing policies related to patient acuity, nurse-to-patient ratios, agency nurse use, overtime, and wages have been found to be related to OC and nurses' ITL (General Accounting Office 2001). Employee characteristics such as gender, education, job experience, and employment status (i.e., part-time versus fulltime) have also been found to be related to both OC and ITL (Marchiori and Henkin 2004). Although previous investigators have found inverse relationships between OC and ITL (Gifford et al. 2002), no research was found that investigated a potential simultaneous relationship between OC and ITL. That is, a poor OC may motivate workers to leave and, at the same time, high turnover may negatively affect employees' perceptions of OC.

The aims of this study were to investigate causes of nurse turnover, as measured by ITL in ICUs, while simultaneously considering OC and identify policy implications. Because hospital nurse shortages are not always institution-wide but concentrated in specialty care areas such as intensive care units (ICUs), understanding causes of turnover in these settings is especially important (Buerhaus et al. 2000). From a policy perspective, it is important to understand whether turnover is related to a tight labor market (i.e., a shortage of personnel and plentiful job alternatives for the nurse), organizational features, or generated by yet unrecognized factors. In a tight labor market, an

Address correspondence to Patricia W. Stone, R.N., M.P.H., Ph.D., Assistant Professor, Columbia University School of Nursing, 617 West 168th Street, New York, NY 10032. Cathy Mooney-Kane, M.P.H., Researcher, is with the Department of Community and Preventive Medicine, University of Rochester. Elaine L. Larson, R.N., Ph.D., C.I.C., Associate Dean of Research, Professor of Pharmaceutical and Therapeutic Research, and Diane K. Pastor, MBA, Doctoral Student, are with the Columbia University School of Nursing. Jack Zwanziger, Ph.D., Professor and Director, is with the Health Policy and Administration School of Public Health, University of IL at Chicago, Chicago, IL. Andrew W. Dick, Ph.D., Senior Economist, is with the Rand Corporation Pittsburgh, PA and is also Adjunct Professor, DCPM, University of Rochester. 
administrator's only option may be to increase wages. On the other hand, if organizational features are the cause of turnover, organizational changes may be needed.

\section{THEORETICAL UNDERPINNINGS}

We developed and tested an instrumental variable model (see Figure 1) that extended past theories and examined a simultaneous relationship between OC and ITL. We identified characteristics that drive both (i.e., employee characteristics and staffing policies), and features that may directly affect one but not the other (i.e., instruments). The instrumental variable for ITL was the nurse labor market. Consistent with previously tested theoretical models postulating that employment alternatives are related to job turnover (Griffeth et al.

Figure 1: Conceptual Framework of Organizational Climate and Nurses' Intent to Leave

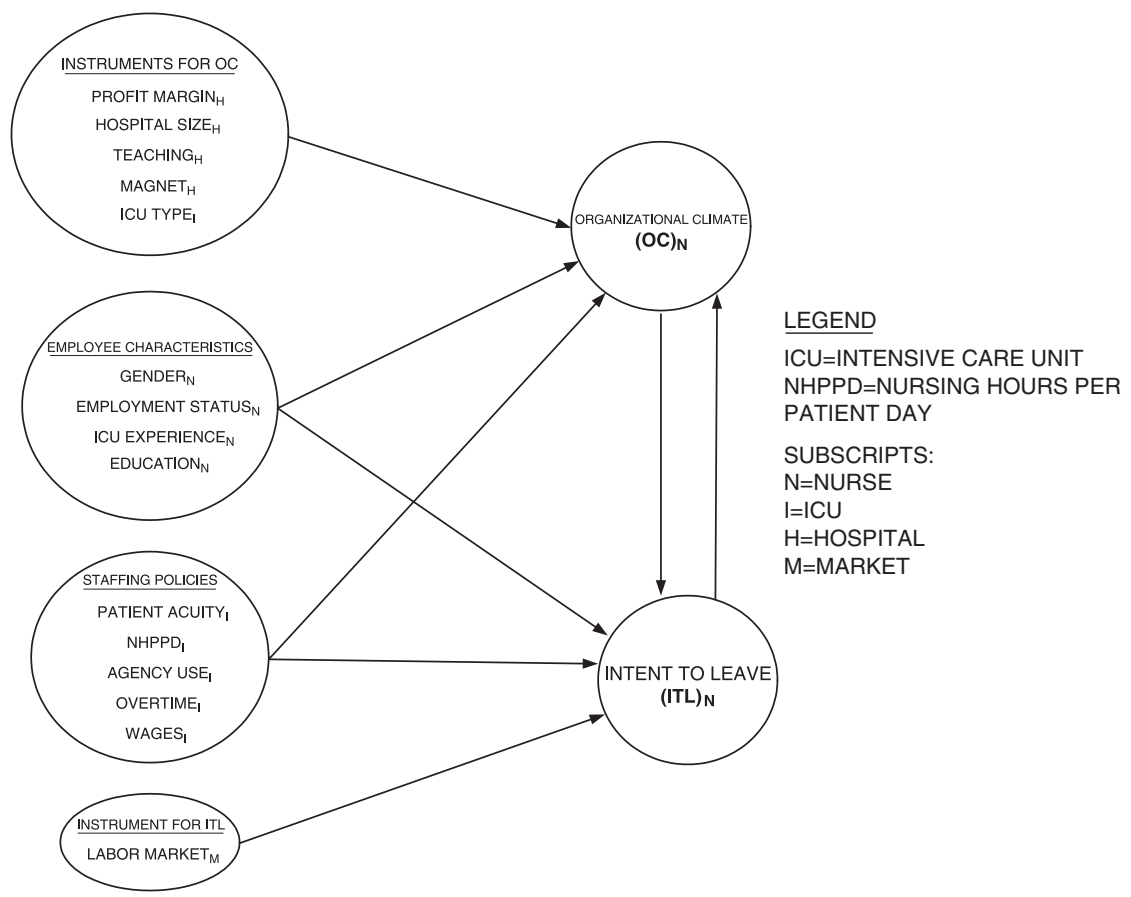


2000), we theorized that the tightness of the regional labor market would have a direct effect on nurses' ITL but would not directly influence perceived OC. Our measure of the regional registered nurse $(\mathrm{RN})$ labor market was the ratio $\mathrm{RN}$ wages to teachers' wages per metropolitan statistical area (MSA). We assumed that teachers' wages were a good control from which to generate relative nurse wages because both occupations are made up of educated, mainly female, professionals. The rationale for using this instrumental variable was that in regions with more competitive salary structures for RNs, the nurse was more likely to perceive alternative employment opportunities resulting in higher ITL, but the labor market was not likely to directly affect the ICU's OC.

A variety of structural characteristics were posited to directly affect $\mathrm{OC}$, but not ITL. These instrumental variables included hospital size, hospital profitability, teaching status, Magnet status, and ICU type. The Magnet accreditation program was developed in the 1980s to recognize excellence in nursing management, philosophy, and nursing care (AACN 2005); therefore, we postulated Magnet status was positively correlated with OC, but only affected ITL through OC. A similar effect of profitability was assumed because unless a hospital is in imminent danger of restructuring or closing, it is unlikely that nurses are aware of a hospital's profitability status. Previous research has determined that nurses employed by a hospital going through a restructuring had no increase in ITL compared to nurses in other hospitals, but they did perceive more work stressors and less job satisfaction (Burke 2005), which offers some empirical evidence to support the use of profitability as an instrument for OC. Setting characteristics such as hospital size, teaching status, and ICU type have been found to be related to nurses' perceptions of the work environment (Shaver and Lacey 2003), but we had no reason to believe they would be related to ITL except through their effect on OC.

The groups of variables postulated to affect both OC and ITL were employee characteristics and staffing policies. The staffing policy variables included patient acuity, nurse hours per patient day, agency use, overtime, and wages. Although the use of overtime and agency nurses may satisfy minimum nurse to patient ratios we believed both staffing strategies may negatively affect the OC as well as promote nurses' ITL. Because patient acuity is a measure of nurse workload we included this as a staffing variable. We postulated that employee characteristics would affect both OC and ITL based on the assumptions that these characteristics are known to influence organizational commitment and mobility of the employee and therefore would affect the outcomes we measured. 


\section{MethodS}

Data were collected from a variety of sources. Table 1 lists variables, operational definitions, and summary statistics. Sampling and data sources are explained below.

\section{Table 1: A List of Variables}

\begin{tabular}{|c|c|c|}
\hline Variable & Operational Definition & Summary Statistics \\
\hline \multicolumn{3}{|c|}{ Instruments for organizational climate } \\
\hline Profit margin & (Revenue - expenses)/revenue & Mean $=0.05(\mathrm{SD}=0.06)$ \\
\hline \multirow[t]{2}{*}{ Hospital size } & Below median bed size & Mean $=278(\mathrm{SD}=91.4)$ \\
\hline & Above median bed size & Mean $=636(\mathrm{SD}=29.7)$ \\
\hline Teaching & Yes teaching hospital & $N=17(74 \%)$ \\
\hline Magnet & Yes Magnet accreditation & $N=4(17 \%)$ \\
\hline \multirow[t]{4}{*}{ ICU type } & Surgical & $N=10(25 \%)$ \\
\hline & Medical/surgical & $N=20(51 \%)$ \\
\hline & Medical & $N=7(18 \%)$ \\
\hline & Coronary & $N=2(5 \%)$ \\
\hline \multicolumn{3}{|l|}{ Instrument for intent to leave } \\
\hline Labor market & $\begin{array}{l}\text { Ratio of teachers' salaries to RN } \\
\text { salaries per MSA }\end{array}$ & Mean $=0.89(\mathrm{SD}=0.09)$ \\
\hline \multicolumn{3}{|l|}{ Employee characteristics } \\
\hline Gender & Male & $N=91(11 \%)$ \\
\hline Education & RN with no bachelors degree & $N=349(42 \%)$ \\
\hline ICU experience (in years) & $\begin{array}{l}\text { Response to the question, } \\
\text { "How many years have you worked } \\
\text { in an ICU?" }\end{array}$ & Mean $=9.2(\mathrm{SD}=8.0)$ \\
\hline \multirow[t]{3}{*}{ Employment status } & Full-time & $N=655(78 \%)$ \\
\hline & Part-time & $N=117(14 \%)$ \\
\hline & Float & $N=64(8 \%)$ \\
\hline \multicolumn{3}{|l|}{ ICU staffing policies } \\
\hline Patient acuity & Mean NIW for Medicare patients & Mean $=3.08(\mathrm{SD}=0.15)$ \\
\hline NHPPD & RN hours per patient day & Mean $=16.4(\mathrm{SD}=3.9)$ \\
\hline Agency use & Yes use of agency nurses & $N=30(77 \%)$ \\
\hline Overtime & Overtime hours/RN hours & Mean $=0.05(\mathrm{SD}=0.03)$ \\
\hline Wage & Mean RN wage adjusted per MSA & Mean $=1.15(\mathrm{SD}=.17)$ \\
\hline \multicolumn{3}{|l|}{ Dependent variables } \\
\hline Organizational climate & PNWE & Mean $=2.91(\mathrm{SD}=0.46)$ \\
\hline Intent to leave & $\begin{array}{l}\text { Positive response to the question, } \\
\text { "Do you plan to leave your current } \\
\text { position in the coming year?" }\end{array}$ & $N=130(15 \%)$ \\
\hline
\end{tabular}

ICU, intensive care unit; RN, registered nurse; BS, bachelors in science; NIW, nursing intensity weight; MSA, metropolitan statistical area; PNWE, perception of nurse work environment; NHPPD, nurse hours per patient day. 


\section{Hospital Sample}

This study was part of a patient safety project in which ICU-related health care associated infections were an important patient safety endpoint. Therefore, recruitment of hospitals occurred through the Association for Professionals in Infection Control and Healthcare Epidemiology, Inc. (APIC) listserve and by invitations sent to hospitals participating in the Centers for Disease Control and Prevention (CDC) National Nosocomial Infections Surveillance (NNIS) system (Horan and Gaynes 2004). Hospitals were eligible to enroll adult medical surgical, medical, surgical, or coronary ICUs that (1) had a minimum of 500 patient days for the year 2002; and (2) conducted infection surveillance using the CDC's definitions. Human subject approvals were obtained from each participating hospital as well as the primary investigators' institutions.

\section{Nurse Sampling}

All RNs employed in an enrolled ICU were eligible to be surveyed using an anonymous self-report questionnaire format. Survey distribution was based on processes developed in previous multisite research surveying health care personnel (Dillman 1978; Smith et al. 1998) and has been described in detail elsewhere (Choi et al. 2004). The overall response rate of 41 percent is comparable to the 38-53 percent response rates recently found in other anonymous multisite surveys of hospital-based nursing personnel (Asch et al. 1997).

\section{Nurse Survey}

Survey data included employee demographics, our measure of OC, and a dichotomous question about the employees' ITL in the coming year. OC was measured using the 42-item Perceived Nurse Work Environment (PNWE) scale (Choi et al. 2004). The PNWE has seven dimensions (e.g., Nurse/Physician Collaboration and Support for Professional Practice), in which respondents are asked to indicate the extent the factor is present in their work environment using a 4-point Likert scale. Internal consistency of the composite scale, which was used in the analysis, was excellent $(\alpha=0.95)$. Higher scores indicated positive perceptions of the OC. Behavioral ITL due to working conditions was measured by a single self-report item, "Do you plan to leave your current position in the coming year?" In previous research of physicians, self-report ITL clinical practice was found to be an adequate marker of actually leaving (73.3 percent sensitivity, 84.4 percent specificity) (Rittenhouse et al. 2004) and is a frequently used in research assessing the nursing workforce (Hayes et al. 2006). Those who expressed their ITL were 
asked why. The majority of respondents indicated reason for ITL to be poor working conditions (53 percent), relocating (15 percent), retirement (5 percent), no reason given (12 percent), and positive career move such as promotion (15 percent). We tested the sensitivity of the results excluding various groups. There were no substantive differences in the results.

\section{Other Data Sources}

Hospitals provided a variety of administrative data for the year 2002 including ICU-specific monthly (1) lists of Medicare patients admitted; (2) total patient census; (3) payroll; (4) use of agency nurses; and (5) self-reported Magnet status as of December 31, 2002. Hospital characteristics such as bed size and teaching status were obtained from the American Hospital Association survey for the year 2002. Profitability was estimated from Medicare cost reports. Labor market tightness was estimated using RNs' and teachers' wages per MSA from the Bureau of Labor Statistics for the same year.

\section{Empirical Framework}

We first estimated naive ordinary least squares equations without considering the simultaneous relationship of ITL and OC. Then using the conceptual framework in Figure 1 we specified a two-equation structural model that identifies causal estimates of the relationships between ITL and OC.

Let

$$
\begin{aligned}
& \mathrm{ITL}=\beta_{1} \mathrm{Z}_{\mathrm{ITL}}+\beta_{2} \mathrm{X}+\beta_{3} \mathrm{OC}+\varepsilon \\
& \mathrm{OC}=\beta_{1} \mathrm{Z}_{\mathrm{OC}}+\beta_{2} X+\beta_{3} \mathrm{ITL}+\varepsilon
\end{aligned}
$$

where $Z$ represents instruments and $X$ refers to the vector of nursing demographic characteristics and ICU staffing policies postulated to effect both ITL and OC. $Z_{\mathrm{OC}}$ refers to a vector of instruments for OC that includes ICU and hospital level characteristics. $Z_{\text {ITL }}$ refers to the instrument for ITL that is the market level variable. In equation $(1)$, the OC effect $\left(\beta_{3}\right)$ on ITL is identified with the exclusion of the $Z_{\mathrm{OC}}$ variables. Similarly, in equation (2), the ITL effect $\left(\beta_{3}\right)$ on OC is identified with the exclusion of the $Z_{\mathrm{ITL}}$ variable.

We estimated each of the equations in the system separately, with the nurse as the unit of analysis. Because responses of nurses working in the same unit may be correlated the models were estimated with robust standard errors clustering on ICU (Huber 1964). To assess endogeneity bias induced by the simultaneous structure proposed, we followed Wooldridge's recommendation to examine the instrumental variable residuals to determine whether the 
differences between the ordinary least squares and instrumental variable coefficients were statistically significant (Wooldridge 2003). Because we had multiple instruments to identify OC effects in the ITL equation, we examined different combinations of $\mathrm{OC}$ instruments and calculated the Hansen $J$ overidentification test statistic to determine whether the final set of instruments performed consistently (Wooldridge 2003). For both OC and ITL we generated $F$ statistics to show the strength of instruments. A Shea partial $R^{2}$ was also computed for both instrumental variable equations (Shea 1997). Finally, to characterize the reduced form, the endogenous variables (ITL and OC) were each expressed as a function of all exogenous variables.

To quantify the magnitude of effects of key significant variables on OC and ITL, we used coefficients from the instrumental variable results to calculate direct, indirect, and total effects of each. For example, direct effects of policy levers were determined by their estimated coefficients (e.g., the direct effect of $X$ on ITL is given by $\beta_{2}$ ). Indirect effects on ITL were the estimated effects of $X$ on OC, and the effect of that change in OC on ITL (analogously for $\mathrm{OC})$. For continuous measures (such as wages), we considered the effects of one standard deviation change. For dichotomous variables (such as teaching status), we considered a change of one unit. The total effect was estimated by summing the direct and indirect effects. To facilitate comparisons between ITL (a dichotomous measure) and OC (a continuous measure), the latter was standardized to a scale from zero to one.

\section{Generalizability of the Sample}

To examine representativeness of the sample we compared age, gender, education level, and employment status (full-time or part-time) of respondents in our sample to the unweighted sample of critical care nurse respondents in the National Sample Survey of Registered Nurses 2000 (HRSA 2000). We regressed the survey response rate on OC, ITL, and setting characteristics. Last, we compared participating hospitals with the national sample of hospitals using American Hospital Association data.

\section{RESULTS}

\section{Sample}

Survey results from $837 \mathrm{RNs}$ employed in 39 ICUs were analyzed. The sample of RNs were of similar age and gender as the national sample of ICU nurses (Table 2) with the majority of the nurses being female (89 percent) and 
Table 2: Comparison to National Data

\begin{tabular}{|c|c|c|c|c|c|}
\hline \multirow[b]{2}{*}{ Registered Nurses } & \multicolumn{2}{|c|}{ Sample $N=837$} & \multicolumn{2}{|c|}{$\begin{array}{c}\text { National Statistics } \\
\quad N=2,645\end{array}$} & \multirow[b]{2}{*}{$p$-value } \\
\hline & $n$ & $\%$ & $n$ & $\%$ & \\
\hline \multicolumn{6}{|l|}{ Age } \\
\hline 29 years & 135 & $(18.3)$ & 481 & $(18.2)$ & \\
\hline $30-44$ years & 384 & $(52.2)$ & 1,416 & $(53.5)$ & \\
\hline $45-59$ years & 212 & $(28.8)$ & 710 & $(26.8)$ & \\
\hline$\geq 60$ years & 5 & $(0.7)$ & 38 & $(1.4)$ & .31 \\
\hline \multicolumn{6}{|l|}{ Gender } \\
\hline Male & 91 & $(10.9)$ & 258 & $(9.8)$ & \\
\hline Female & 746 & $(89.1)$ & 2,387 & $(90.2)$ & .35 \\
\hline \multicolumn{6}{|l|}{ Education } \\
\hline Associate & 277 & $(33.1)$ & 948 & $(35.9)$ & \\
\hline Diploma & 72 & $(8.6)$ & 386 & $(14.6)$ & \\
\hline Bachelors & 436 & $(52.1)$ & 1,205 & $(45.5)$ & \\
\hline Graduate & 52 & $(6.2)$ & 102 & $(3.9)$ & $<.0001$ \\
\hline \multicolumn{6}{|l|}{ Employment status } \\
\hline Full-time & 656 & $(78.4)$ & 1,915 & $(72.4)$ & \\
\hline \multirow[t]{2}{*}{ Part-time } & 181 & $(21.6)$ & 730 & $(27.6)$ & .001 \\
\hline & \multicolumn{2}{|c|}{$N=23$} & \multicolumn{2}{|c|}{$N=4,859$} & \\
\hline Hospitals & $n$ & $\%$ & $n$ & $\%$ & \\
\hline \multicolumn{6}{|l|}{ Region } \\
\hline Atlantic & 6 & $(26.09)$ & 1,403 & $(28.74)$ & \\
\hline Central & 11 & $(47.83)$ & 2,516 & $(51.78)$ & \\
\hline Pacific & 6 & $(26.09)$ & 940 & (19.35) & .72 \\
\hline \multicolumn{6}{|l|}{ Size } \\
\hline Under 300 beds & 8 & $(34.78)$ & 4,118 & $(83.82)$ & \\
\hline 300-399 beds & 3 & (13.04) & 346 & $(7.04)$ & \\
\hline 400 or more beds & 12 & $(52.17)$ & 449 & $(9.14)$ & $<.0001$ \\
\hline \multicolumn{6}{|l|}{ Teaching status } \\
\hline Yes & 6 & $(26.09)$ & 328 & (6.68) & \\
\hline No & 17 & (73.91) & 4,585 & (93.32) & .0002 \\
\hline
\end{tabular}

Note: National sample of RN data comes from National Sample Survey of Registered Nurses (NSSRN) 2000. National sample of hospital data comes from the American Hospital Association. Data displayed are means and standard deviations for continuous variables and sample size and percentages for nominal variables. Differences were tested using $\chi^{2}$ analysis.

$\mathrm{RN}$, registered nurse.

between 30 and 44 years old (52 percent). In the national sample, the RNs were less educated and a higher proportion worked part-time ( $p$-values $<.05$ ). The 39 ICUs were located in 23 hospitals (number of ICUs per hospital ranged from 1 to 5). Similar to the hospitals participating in the CDC's NNIS system (Table 2), the hospitals participating in our study were geographically 
representative of the nation, but they were larger and were more likely to be affiliated with an academic institution than other hospitals in the nation (Richards et al. 2001). The ICU specific survey response rates were not significantly related to the dependent variables or setting characteristics.

Tables 3 and 4 display the regression results for ITL and OC, respectively. From left to right, the columns list the results of the naive ordinary least squares, instrumental variables, and reduced form models. The Wooldridge tests were not significant, implying that we should not reject the hypothesis that there is no endogeneity in either equation. Although our statistical tests for endogeneity failed to reject the ordinary least square estimates as significantly different, some of estimates in the instrumental variable specification were quite different.

\section{Intent to Leave (ITL)}

Overall, the ITL equations were similar (Table 3). In the ordinary least squares equation, OC was significantly inversely related to ITL $(p<.001)$. The instrumental variable estimate of the $\mathrm{OC}$ effect was also significantly negative $(p \leq .05)$; and, although not statistically significantly different from the ordinary least square estimate, more than 50 percent larger in magnitude. The $F$ test of the OC instruments was significant $\left(F_{(13,26)}=2.54, p=.03\right)$, the Shea partial $R^{2}$ was large (0.09), and the over-identification test failed to reject the null that the instruments are appropriate $(p=.89)$.

In the OC reduced form model (Table 4), three OC instruments (profitability, teaching status, and Magnet accreditation) were statistically significant. Our results did not change substantively when we eliminated different combinations of the statistically insignificant instruments (data not displayed). The labor market was a negative, large, and statistically significant $(p \leq .05)$ predictor of ITL in the reduced form equation. It was also negative, statistically significant $(p \leq .05)$, and nearly as large in the instrumental variable equation.

Overall, nursing experience was significantly related to ITL $\left(F_{(9,38)}=2.64, p=.02\right)$. Nurses with less than 1 year experience and between 10 and 11.5 years experience were significantly less likely to indicate ITL than those with $1-1.5$ years experience $(p$-values $<.05)$. The reduced form specification was similar to the instrumental variable model results.

\section{Organizational Climate (OC)}

Table 4 contains the estimation results from the three OC models. In the ordinary least squares model, the ITL coefficient was negative and statistically 
Table 3: Results for Intent to Leave (ITL)

\begin{tabular}{|c|c|c|c|c|c|c|}
\hline \multirow[b]{2}{*}{ Variable } & \multicolumn{2}{|c|}{$\begin{array}{c}\text { Naive Ordinary Least } \\
\text { Squares }\end{array}$} & \multicolumn{2}{|c|}{$\begin{array}{l}\text { Instrumental } \\
\text { Variable }\end{array}$} & \multicolumn{2}{|c|}{$\begin{array}{l}\text { Reduced Form } \\
\text { Ordinary Least } \\
\quad \text { Squares }\end{array}$} \\
\hline & Coefficient & $S E$ & Coefficient & $S E$ & Coefficient & $S E$ \\
\hline $\begin{array}{l}\text { Organizational climate } \\
\text { (OC) }\end{array}$ & -0.136 & $0.032 * * * *$ & -0.274 & $0.071^{* * * *}$ & - & - \\
\hline \multicolumn{7}{|l|}{$X:$ Employee characteristics } \\
\hline Gender (male) & 0.013 & 0.045 & 0.008 & 0.044 & 0.023 & 0.048 \\
\hline Education (no BSN) & -0.037 & 0.025 & -0.038 & 0.027 & -0.034 & 0.026 \\
\hline \multicolumn{7}{|l|}{ Experience (in years) ${ }^{\dagger}$} \\
\hline Less than 1 & -0.133 & $0.048^{* *}$ & -0.118 & $0.045^{* *}$ & -0.118 & $0.051^{\text {*** }}$ \\
\hline $2-2.75$ & 0.022 & 0.046 & 0.021 & 0.041 & 0.021 & 0.048 \\
\hline $3-4.75$ & 0.056 & 0.074 & 0.015 & 0.073 & 0.040 & 0.075 \\
\hline $5-6.5$ & -0.011 & 0.052 & -0.021 & 0.047 & -0.005 & 0.056 \\
\hline $7-9.5$ & 0.029 & 0.065 & 0.015 & 0.064 & 0.036 & 0.067 \\
\hline $10-11.5$ & -0.115 & $0.047^{*}$ & -0.125 & $0.047^{* *}$ & -0.102 & $0.048^{*}$ \\
\hline $12-14.5$ & -0.065 & 0.058 & -0.069 & 0.052 & -0.064 & 0.062 \\
\hline $15-19.5$ & -0.079 & 0.052 & -0.104 & 0.051 & -0.057 & 0.054 \\
\hline $20-29.5$ & -0.070 & 0.048 & -0.084 & 0.045 & -0.056 & 0.050 \\
\hline $30-45$ & 0.032 & 0.102 & 0.048 & 0.101 & 0.022 & 0.104 \\
\hline \multicolumn{7}{|l|}{ Employment status ${ }^{\ddagger}$} \\
\hline Full-time & 0.040 & 0.047 & 0.043 & 0.047 & 0.046 & 0.049 \\
\hline Part-time & 0.069 & 0.066 & 0.061 & 0.067 & 0.088 & 0.071 \\
\hline \multicolumn{7}{|l|}{$X$ : Staffing policies } \\
\hline Patient acuity & 0.005 & 0.124 & 0.098 & 0.148 & -0.026 & 0.178 \\
\hline NHPPD & -0.003 & 0.002 & -0.003 & 0.001 & 0.003 & 0.004 \\
\hline Agency & 0.034 & 0.032 & 0.029 & 0.027 & 0.078 & 0.042 \\
\hline Overtime & 0.005 & 0.004 & 0.006 & 0.003 & 0.009 & 0.005 \\
\hline Nurses' wages & 0.077 & 0.068 & 0.188 & $0.083^{*}$ & -0.057 & 0.990 \\
\hline \multicolumn{7}{|l|}{$Z_{\mathrm{OC}}:$ OC instruments } \\
\hline \multicolumn{7}{|l|}{ Hospital characteristics } \\
\hline \multicolumn{7}{|l|}{ Size } \\
\hline Below median & - & - & - & - & 0.033 & 0.018 \\
\hline Above median & - & - & - & - & 0.009 & 0.007 \\
\hline Profitability & - & - & - & - & -0.126 & 0.273 \\
\hline Teaching status & - & - & - & - & 0.038 & 0.052 \\
\hline Magnet & - & - & - & - & -0.076 & 0.045 \\
\hline \multicolumn{7}{|l|}{ ICU characteristics } \\
\hline \multicolumn{7}{|l|}{ ICU type } \\
\hline Surgical & - & - & - & - & -0.023 & 0.045 \\
\hline Medical & - & - & - & - & 0.022 & 0.051 \\
\hline Coronary & - & - & - & - & -0.030 & 0.057 \\
\hline \multicolumn{7}{|l|}{$Z_{\text {ITL }}:$ ITL instrument } \\
\hline Labor market & -0.266 & $0.106^{*}$ & -0.300 & $0.099^{* * *}$ & -0.341 & $0.121^{*}$ \\
\hline
\end{tabular}


Table 3. Continued

\begin{tabular}{|c|c|c|c|c|c|c|}
\hline \multirow[b]{2}{*}{ Variable } & \multicolumn{2}{|c|}{$\begin{array}{c}\text { Naive Ordinary Least } \\
\text { Squares }\end{array}$} & \multicolumn{2}{|c|}{$\begin{array}{c}\text { Instrumental } \\
\text { Variable }\end{array}$} & \multicolumn{2}{|c|}{$\begin{array}{c}\text { Reduced Form } \\
\text { Ordinary Least } \\
\quad \text { Squares }\end{array}$} \\
\hline & Coefficient & $S E$ & Coefficient & $S E$ & Coefficient & $S E$ \\
\hline $\begin{array}{l}\text { Wooldridge test for } \\
\text { endogeneity }\end{array}$ & & & $0.09(p=.30)$ & & & \\
\hline Strength of instruments & & & & & & \\
\hline Shea partial $R^{2}$ & & & 0.0081 & & & \\
\hline$F$ test & & & $7.94(p=.02)$ & & & \\
\hline
\end{tabular}

Notes: The naive ordinary least squares regression does not consider a simultaneous relationship between ITL and OC. In the instrumental variable regression this relationship was considered and the value for $\mathrm{OC}$ was predicted based on the $\mathrm{OC}$ instruments' coefficients from the reduced form results (see Table 4). All models are estimated with robust standard errors clustering for intensive care unit with the nurse as the unit of analysis. BSN, bachelor of science; NHPPD, nurse hours per patient day; ICU, intensive care unit.

$* p$-value $\leq .05$,

$* *$-value $<.01$,

***** $p$-value $<.001$.

${ }^{\dagger}$ Referent group nurses with $1-1.5$ years experience.

${ }^{\ddagger}$ Referent group float nurses.

significant $(p<.001)$, suggesting a strong and important inverse relationship. We could not, however, confirm this relationship with the instrumental variable model where the estimate of the ITL effect was small, positive, and very imprecisely estimated ( $\mathrm{SE}=0.695)$. Although the instrument (labor market) is statistically significant and substantively important in the ITL equation (Table 3 ), this could be evidence that it is a weak instrument. In fact, the partial $R^{2}$ statistic was very small, supporting this concern.

In each of the OC models, we found average nurses' wages in the ICU, hospital profitability, and Magnet status had strong positive and statistically significant effects on OC, and hospital teaching status had a significant negative effect (all $p$-values $\leq .05)$ on OC. Overall, nursing experience was significantly related to $\mathrm{OC}\left(F_{(9,38)}=2.22, p=.05\right)$. The point estimates in the ordinary least squares and the reduced form models are negative for nurses with 15-19.5 years of experience compared to those with 1-1.5.

\section{Impact of Key Variables}

The variable with the largest substantive impact on ITL is the OC (see online Appendix); improving the OC by one standard deviation was predicted to reduce nurse's probability of ITL their position by 13 percentage points. The 
Table 4: Results for Organizational Climate (OC)

\begin{tabular}{|c|c|c|c|c|c|c|}
\hline \multirow[b]{2}{*}{ Variable } & \multicolumn{2}{|c|}{$\begin{array}{c}\text { Naive Ordinary Least } \\
\text { Squares }\end{array}$} & \multicolumn{2}{|c|}{ Instrumental Variable } & \multicolumn{2}{|c|}{$\begin{array}{l}\text { Reduced Form } \\
\text { Ordinary Least } \\
\quad \text { Squares }\end{array}$} \\
\hline & Coefficient & $(S E)$ & Coefficient & $S E$ & Coefficient & $S E$ \\
\hline Intent to leave (ITL) & -0.170 & $0.037^{* * *}$ & -0.135 & 0.659 & & \\
\hline \multicolumn{7}{|c|}{$X:$ Employee characteristics } \\
\hline Gender (male) & -0.063 & 0.060 & -0.064 & 0.058 & -0.067 & 0.061 \\
\hline Education (no BSN) & -0.004 & 0.032 & 0.005 & 0.043 & 0.010 & 0.033 \\
\hline \multicolumn{7}{|c|}{ Experience (in years) ${ }^{\dagger}$} \\
\hline Less than 1 & 0.128 & 0.071 & 0.134 & 0.134 & 0.155 & 0.074 \\
\hline $2-2.75$ & 0.020 & 0.070 & 0.019 & 0.060 & 0.017 & 0.073 \\
\hline $3-4.75$ & -0.078 & 0.063 & -0.080 & 0.060 & -0.088 & 0.067 \\
\hline $5-6.5$ & -0.060 & 0.074 & -0.053 & 0.088 & -0.059 & 0.080 \\
\hline $7-9.5$ & -0.068 & 0.086 & -0.069 & 0.076 & -0.073 & 0.091 \\
\hline $10-11.5$ & -0.099 & 0.091 & -0.096 & 0.079 & -0.082 & 0.093 \\
\hline $12-14.5$ & -0.032 & 0.071 & -0.030 & 0.090 & -0.021 & 0.076 \\
\hline $15-19.5$ & -0.166 & $0.071^{*}$ & -0.163 & 0.087 & -0.156 & $0.076^{*}$ \\
\hline $20-29.5$ & -0.010 & 0.063 & -0.098 & 0.084 & -0.090 & 0.068 \\
\hline $30-45$ & .0917 & 0.108 & 0.091 & 0.105 & 0.195 & 0.111 \\
\hline \multicolumn{7}{|l|}{ Employment status ${ }^{\ddagger}$} \\
\hline Full-time & 0.012 & 0.052 & -0.010 & 0.061 & 0.004 & 0.051 \\
\hline Part-time & -0.088 & 0.060 & -0.090 & 0.074 & -0.102 & 0.061 \\
\hline \multicolumn{7}{|l|}{$X$ : Staffing policies } \\
\hline Patient acuity & 0.666 & 0.374 & 0.668 & 0.361 & 0.672 & 0.370 \\
\hline NHPPD & -0.054 & 0.008 & -0.015 & 0.008 & -0.016 & 0.009 \\
\hline Agency & -0.200 & 0.100 & -0.203 & 0.118 & -0.213 & 0.105 \\
\hline Overtime & -0.002 & 0.010 & -0.002 & 0.104 & -0.004 & 0.009 \\
\hline Nurses' wages & 1.027 & $0.248^{* * * *}$ & 1.028 & $0.250^{* * * *}$ & 1.035 & $0.253^{* * * * *}$ \\
\hline \multicolumn{7}{|l|}{$Z_{\mathrm{OC}}:$ OC instruments } \\
\hline \multicolumn{7}{|c|}{ Hospital characteristics } \\
\hline \multicolumn{7}{|l|}{ Size } \\
\hline Below median & -0.094 & 0.055 & -0.094 & 0.058 & -0.099 & 0.057 \\
\hline Above median & -0.033 & 0.017 & -0.033 & $0.017^{*}$ & -0.034 & 0.018 \\
\hline Profitability & 1.246 & $0.480 *$ & 1.250 & $0.467^{* * *}$ & 1.267 & $0.500 *$ \\
\hline Teaching status & -0.275 & $0.124^{*}$ & -0.277 & $0.128^{*}$ & -0.281 & $0.134^{*}$ \\
\hline Magnet & 0.257 & $0.083^{* *}$ & 0.253 & $0.083^{* * *}$ & 0.253 & $0.092^{* * *}$ \\
\hline \multicolumn{7}{|l|}{ ICU characteristics } \\
\hline \multicolumn{7}{|l|}{ ICU type } \\
\hline Surgical & -0.021 & 0.065 & -0.020 & 0.064 & -0.017 & 0.067 \\
\hline Medical & -0.084 & 0.117 & -0.083 & 0.114 & -0.086 & 0.120 \\
\hline Coronary & 0.075 & 0.153 & 0.076 & 0.076 & 0.080 & 0.159 \\
\hline \multicolumn{7}{|l|}{$Z_{\mathrm{ITL}}:$ ITL instrument } \\
\hline Labor market & - & - & - & - & 0.046 & 0.240 \\
\hline $\begin{array}{l}\text { Wooldridge test for } \\
\text { endogeneity }\end{array}$ & & & $-0.22(p=.80)$ & & & \\
\hline
\end{tabular}


Table 4. Continued

\begin{tabular}{|c|c|c|c|c|c|c|}
\hline \multirow[b]{2}{*}{ Variable } & \multicolumn{2}{|c|}{$\begin{array}{c}\text { Naive Ordinary Least } \\
\text { Squares }\end{array}$} & \multicolumn{2}{|c|}{ Instrumental Variable } & \multicolumn{2}{|c|}{$\begin{array}{c}\text { Reduced Form } \\
\text { Ordinary Least } \\
\quad \text { Squares }\end{array}$} \\
\hline & Coefficient & $(S E)$ & Coefficient & $S E$ & Coefficient & $S E$ \\
\hline $\begin{array}{l}\text { Hansen } J \text { statistic for } \\
\text { over identification }\end{array}$ & & & $2.91(p=.89)$ & & & \\
\hline Strength of instruments & & & & & & \\
\hline Shea partial $R^{2}$ & & & 0.09 & & & \\
\hline$F$ test & & & $2.54(p=.084)$ & & & \\
\hline
\end{tabular}

Notes: The naive ordinary least squares regression does not consider a simultaneous relationship between ITL and OC. In the instrumental variable regression this relationship was considered and the value for ITL was predicted based on the ITL instrument coefficient from the reduced form results (see Table 3). All models are estimated with robust standard errors clustering for intensive care unit with the nurse as the unit of analysis. BSN, bachelor of science; NHPPD, nurse hours per patient day; ICU, intensive care unit.

$* p$-value $\leq .05$,

$* *$-value $<.01$,

***** $p$-value $<.001$.

${ }^{\dagger}$ Referent group nurses with $1-1.5$ years experience.

${ }^{\ddagger}$ Referent group float nurses.

variable with the largest total impact on OC was Magnet status. Being employed in a Magnet hospital was predicted to improve the OC by approximately 8.4 percentage points. Because of the positive effect of wages on OC and the large effect of OC on ITL, a wage increase should have small total effect on decreasing ITL.

\section{DISCUSSION}

Fifteen percent of the nurses in our sample indicated ITL in the coming year, imposing potentially high hiring and training costs on hospitals. Using instrumental variable techniques, causal relationships were postulated to explain ITL and OC, and we estimated these relationships empirically to quantify the role that OC, labor market conditions, and staffing policies play on ITL. Based on the structural model estimates, we found strong evidence that $\mathrm{OC}$ and the tightness of the labor market have significant roles in determining ITL. Furthermore, OC was strongly affected by the average regionally adjusted ICU wages, hospital profitability, teaching, and Magnet status. This implies that nurses' working environments may be affected by investments in human resources, which may ultimately affect nurses' ITL. 
A growing body of evidence suggests relationships between increasing nurse staffing and positive patient outcomes (Aiken et al. 2002; Needleman et al. 2002; Institute of Medicine 2004; Mark et al. 2004). We did not find nurse hours per patient day to be significantly associated with either OC or ITL. This may be due to contradictory effects or interactions between cognitive stimulation, workload, and job enjoyment (Oldham and Gordon 1999), the focus on ICUs (not hospital-wide staffing), and/or imprecision due to lack of power. Future analyses investigating the relationships between staffing load, OC, ITL, and patient outcomes are warranted.

Hospital profitability was significantly positively related to OC. More profitable hospitals may have better senior management, which may affect myriad processes in the hospital including those captured by our measure of OC. Furthermore, more profitable hospitals may have more capital for infrastructure, support staff for building maintenance and housekeeping, or more opportunities for continuing education, all of which may improve OC. The exact mechanism of this effect was beyond the scope of this study.

\section{Limitations}

The structural model posited critically depends on the assumptions about the instrumental variables: that they are strongly correlated with the endogenous right-hand-side variables, and that they do not directly cause the dependent variable. As required for estimating precise structural effects of OC on ITL, our OC instruments were strong predictors. Our main results about the role of $\mathrm{OC}$ in ITL were quite robust to variations in the specification of instruments. Our ITL instrument, however, was not as strong a predictor, which could explain the large standard errors in the structural estimates of ITL on OC and the results about the role of ITL on OC. The instrumental variable estimates were based on a single instrument that was a substantively strong predictor of ITL, but was relatively imprecisely estimated $(\mathrm{SE}=0.14, p=.05)$. However, the instrumental variable estimates were too dissimilar from the naive ordinary least squares estimates to simply ignore. Further analyses using a larger sample size with improved instruments would be helpful in understanding if this result is due to lack of power, poor model specification, and/or true lack of effect of ITL on OC.

Although this study used a unique, comprehensive, dataset that included multiple levels of data including characteristics related to the nurse, the ICU, the hospital, and the labor market, inherent limitations of the study were the size of the dataset and the survey response rate. The results may be biased with 
those intending to leave less likely to respond, especially since some researchers have found nurse turnover rates to be higher than we found in this sample (Hayes et al. 2006). However, the response rate was not related to either dependent variables or setting characteristics; therefore we believe this potential bias is most likely minimal. Because of the self-selected nature of the hospitals and the focus on the ICU environment, the results may not be generalizable in other settings. The sample of nurses in our study was of a similar age and gender as a national sample of critical care nurses. Additionally, the geographical representativeness of the hospitals leads us to believe that the sample was representative of full-time nurses working in ICUs in large academic health centers. However, the results may not be generalizable to smaller, nonacademic hospitals and other settings outside of the ICU. It was not surprising that the hospitals that participated were mainly larger teaching hospitals, as they reflect the NNIS hospitals, which was a primary enrollment strategy used. Although a random sampling of hospitals may have provided more community-based hospitals, these hospitals may not have had the infrastructure required to provide the needed data elements. Furthermore, large teaching hospitals are important to study as OC was perceived more negatively in these settings.

The cross-sectional nature of the data and use of ITL (a proxy for turnover) were limitations. Although ITL is thought to be one of the best predictors of actual turnover (Griffeth et al. 2000; Heyes 2003), it is not a perfect correlate. Studying the relationships of interest using longitudinal data with actual turnover would be a great improvement. However, this was not feasible. Some systems are routinely collecting data on OC, but such data are not collected by most hospitals (Kam and Sincere 1999). Many hospitals are contributing data to the National Database of Nursing Quality Indicators (NDNQIs), which has adapted measures of nurses' perceptions of work environment (Gallagher and Rowell 2003). A similar measure has also been endorsed by the National Quality Forum (2004). In future research, it may be possible to link existing databases with human resource data to provide longitudinal analyses.

Last, our measure of nurse labor market was the ratio of $\mathrm{RN}$ wages per MSA to teacher wages per MSA. Because we were not interested in measuring whether a nursing market is more or less tight than any other market in a given area, but rather whether a nursing market in an MSA is more or less tight than a nursing market in another MSA, we believed the measure was adequate. No single empirical measure of occupational labor shortages exists and the existing national datasets are not thought to be sensitive to local labor markets, especially for nursing (Veneri 1999). We followed previous researchers 
method of comparing average wages of nurses in a local area compared with a profession of similar gender and educational level, that is teaching (Nowak and Preston 2001), but this measure may be a limitation to the study.

\section{Policy Implications}

Despite these limitations, the results have a number of policy implications. We believe that health administrators and policy makers should implement interventions aimed at improving OC. As reported by the International Council of Nurses (2006), positive nurse work environments are a result of multiple organizational and structural factors such as the leadership vision and organization characteristics (e.g., communication processes in place) as well as immediate supervisor processes, work design, and group behavior such as team collaboration. Although the analyses reported here do not tease out differences and relative importance of one factor (or subclimate) over another, the analyses do point to the overall importance of a positive OC. Previously, we have found that the nurses' perceptions of professional practice and clinical competence of other nurses were important factors relating to ITL (Stone et al. 2006) and that nurses employed in hospitals with Magnet accreditation perceive the OC more positively (Cimiotti et al. 2005). However, longitudinal research is needed to examine exactly how obtaining Magnet accreditation changes work environments, and continued development and testing of interventions aimed at improving $\mathrm{OC}$ are needed.

Increasing wages without attention to the underlying $\mathrm{OC}$ may not be the most cost effective way to reduce nurse turnover rates. Others have come to a similar conclusion; in England, researchers found that nurses' dissatisfaction with promotion had a stronger impact than pay on intent to quit (Shields and Ward 2001). Therefore, the researchers concluded that efficient policy design must not only focus on improved pay, but also concentrate on improving career opportunities.

Lastly, nurses employed in teaching hospitals had a higher probability of having a negative perception of the $\mathrm{OC}$ in their work environment. In teaching hospitals with rotations of interns and residents, collaboration may be more difficult due to the lack of stability in the interdisciplinary team. Administrators and health policy makers in these institutions need to pay close attention to the $\mathrm{OC}$ within their setting.

\section{CONCLUSION}

Nursing turnover is an important problem in acute care hospitals. With the backdrop of the nursing shortage and the costs associated with turnover, 
hospital administrators must find ways to become employers of choice if they are going to recruit and retain nurses. While improving nurse wages may help, it is insufficient. Our findings suggest that implementing interventions aimed at ensuring a positive $\mathrm{OC}$ may be a more effective strategy.

\section{ACKNOWLEDGMENTS}

This study was funded by AHRQ R01 HS013114. We thank all the hospitals that participated in this research. We also thank T. Horan who assisted with recruitment and data collection; $H$. Shih who assisted with data analysis; and T. Horan and D. Scott who reviewed prior drafts of the manuscript as well as the anonymous reviewers and editors who gave thoughtful suggestions.

Disclosures: The authors have no conflicts of interest.

Disclaimers: The authors have no disclaimers.

\section{REFERENCES}

AACN. 2005. AACN Standards for Establishing and Sustaining Healthy Work Environments. Aliso Viejo, CA: AACN.

Aiken, L. H., S. P. Clarke, D. M. Sloane, J. Sochalski, and J. H. Silber. 2002. "Hospital Nurse Staffing and Patient Mortality, Nurse Burnout, and Job Satisfaction.” Journal of the American Medical Association 288: 1987-93.

Asch, D. A., M. K. Jedrziewski, and N. A. Christakis. 1997. "Response Rates to Mail Surveys Published in Medical Journals.” Journal of Clinical Epidemiology 50: 112936.

Buerhaus, P. I., D. O. Staiger, and D. I. Auerbach. 2000. "Why Are Shortages of Hospital RNs Concentrated in Specialty Care Units?” Nursing Economics 18: 1116.

Burke, R. J. 2005. "Correlates of Nursing Staff Survivor Responses to Hospital Restructuring and Downsizing." Health Care Management (Frederick) 24: 141-9.

Choi, J., S. Bakken, E. Larson, Y. Du, and P. W. Stone. 2004. "Perceived Nursing Work Environment." Nursing Research 53: 370-8.

Cimiotti, J., P. Quinlan, E. Larson, D. Pastor, S. Lin, and P. W. Stone. 2005. "The Magnet Processes and the Perceived Work Environment of Nurses." Nursing Research 54: 384-90.

Dillman, D. 1978. Mail and Telephone Surveys: The Total Design Method. New York: Wiley.

Gallagher, R. M., and P. A. Rowell. 2003. "Claiming the Future of Nursing through Nursing-Sensitive Quality Indicators.” Nursing Administraction Quarterly 27: 27384 .

General Accounting Office. 2001. Nursing Workforce: Recruitment and Retention of Nurses and Nurse Aides Is a Growing Concern. GAO-01-750T. Washington, DC: United States General Accounting Office. 
Gifford, B. D., R. F. Zammuto, and E. Al. Goodman. 2002. "The Relationship between Hospital Unit Culture and Nurses Quality of Work Life." Journal of Healthcare Management 47: 13-25.

Griffeth, R. W., P. W. Hom, and S. Gaertner. 2000. “A Meta-Analysis of Antecedents and Correlates of Employee Turnover: Update, Moderator Tests, and Research Implications for the Next Millennium." Journal of Management 26: 463-88.

Griffeth, R. W., R. P. Steel, D. G. Allen, and N. Bryan. 2005. "The Development of a Multidimensional Measure of Job Market Cognitions: The Employment Opportunity Index (EOI)." Journal of Applied Psychology 90: 335-49.

Hayes, L. J., L. O'Brien-Pallas, C. Duffield, J. Shamian, J. Buchan, F. Hughes, H. K. Spence Laschinger, N. North, and P. W. Stone. 2006. "Nurse Turnover: A Literature Review." International Journal of Nursing Studies 43: 237-63.

Heyes, A. 2003. The Economics of Vocation or Why Is a Badly Paid Nurse a Good Nurse? Royal Holloway: University of London.

Horan, T. C., and R. P. Gaynes. 2004. "Surveillance of Nosocomial Infections." In Hospital Epidemiology and Infection Control, edited by C. Glen Mayhall, pp. 1659-702. Philadelphia: Lippincott Williams \& Wilkins.

HRSA. 2000. The National Sample Survey of Registered Nurses 2000. Rockville, MD: Bureau of Health Professions, Health Resources and Services Administration.

Huber, P. 1964. "Robust Estimation of a Location Parameter." Annals of Mathematical Statistics 35: 73-101.

Institute of Medicine. 2004. Keeping Patients Safe: Transforming the Work Environment of Nurses. Washington, DC: National Academy Press.

International Council of Nurses and the Florence Nightingale International Foundation. 2006. The Global Nursing Shortage: Priority Areas for Intervention. Geneva: The Global Nursing Review Initiative.

Kam, S., and F. Sincere. 1999. "Using Information from Linkage Research Studies to Improve Organizational Performance." Permanente Journal 3: 54-7.

Marchiori, D. M., and A. B. Henkin. 2004. "Organizational Commitment of a Health Profession Faculty: Dimensions, Correlates and Conditions." Medical Teacher 26: 353-8.

Mark, B. A., D. W. Harless, M. McCue, and Y. Xu. 2004. "A Longitudinal Examination of Hospital Registered Nurse Staffing and Quality of Care." Health Services Research 39: 279-300.

Mor Barak, M. E., J. A. Nissly, and A. Levin. 2001. "Antecedents to Retention and Turnover among Child Welfare, Social Work and Other Human Service Employees: What Can We Learn from Past Research? A Review and MetaAnalysis." Social Service Review 75: 625-61.

National Quality Forum. 2004. National Voluntary Consensus Standards for Nursing-Sensitive Care: An Initial Performance Measure Set. Washington, DC: National Quality Forum.

Needleman, J., P. Buerhaus, S. Mattke, M. Stewart, and K. Zelevinsky. 2002. "NurseStaffing Levels and the Quality of Care in Hospitals." New England Journal of Medicine 346: 1715-22.

Nowak, M. J., and A. C. Preston. 2001. "Can Human Capital Theory Explain Why Nurses Are So Poorly Paid?” Australian Economic Paper March 40(2): 232-45. 
Oldham, G. R., and B. I. Gordon. 1999. "Job Complexity and Employee Substance Use: The Moderating Effects of Cognitive Ability." Journal of Health Society Behavior 40: 290-306.

Richards, C., T. G. Emori, J. Edwards, S. Fridkin, J. Tolson, and R. Gaynes. 2001. "Characteristics of Hospitals and Infection Control Professionals Participating in the National Nosocomial Infections Surveillance System 1999.” American Journal of Infection Control 29: 400-3.

Rittenhouse, D. R., E. Mertz, D. Keane, and K. Grumbach. 2004. "No Exit: An Evaluation of Measures of Physician Attrition." Health Services Research 39: 1571-88.

Shaver, K. H., and L. M. Lacey. 2003. "Job and Career Satisfaction among Staff Nurses: Effects of Job Setting and Environment.” Journal of Nursing Administration 33: 166-72.

Shea, J. 1997. "Instrument Relevance in Multivariate Linear Models: A Simple Measure." Review of Economics and Statistics 49: 348-52.

Shields, M. A., and M. Ward. 2001. "Improving Nurse Retention in the National Health Service in England: The Impact of Job Satisfaction on Intentions to Quit." Journal of Health Economics 20: 677-701.

Smith, C. S., J. Salyer, N. Geddes, and B. A. Mark. 1998. "Strategies to Enhance Internal Validity in Multi-Center Longitudinal Research.” Outcomes Management and Nurse Practitioner 2: 174-9.

Stone, P. W., M. I. Harrison, P. Feldman, M. Linzer, T. Peng, D. Roblin, J. ScottCawiezell, N. Warren, and E. Williams. 2005. "Organizational Climate of Staff Working Conditions and Safety-An Integrative Model." Advances in Patient Safety: From Research to Implementation 2: 467-81.

Stone, P. W., E. Larson, C. Mooney-Kane, S. Lin, and A. Dick. 2006. "Organizational Climate and ICU Nurses' Intention to Leave.” Critical Care Medicine 34: 1907-12.

Veneri, C. M. 1999. “Can Occupational Labor Shortages Be Identified Using Available Data?" Monthly Labor Review 122(3): 15-21.

Wooldridge, J. M. 2003. Introductory Econometrics: A Modern Approach. Mason, OH: South-Western.

\section{SUPPLEMENTARY MATERIAL}

The following supplementary material for this article is available online: Appendix: Impact of Key Variables on Outcomes.

This material is available as part of the online article from:

http://www.blackwell-synergy.com/doi/abs/10.1111/j.1475-6773.2006.00651.x (This link will take you to the article abstract).

Please note: Blackwell Publishing is not responsible for the content or functionality of any supplementary materials supplied by the authors. Any queries (other than missing material) should be directed to the corresponding author for the article. 